\title{
Removal Effect of A/O SBR Process for Soybean Wastewater
}

Jinlong Zuo

Research Center on Life Science and Environmental

Science, Department of Environmental

Engineering,Harbin University of Commerce

Engineering Research Center of Natural Anticancer

Drugs, Ministry of Education

Harbin, China

Email: mdjzjl@163.com

Junxia Wang

Research Center on Life Science and Environmental Science

Engineering Research Center of Natural Anticancer Drugs , Ministry of Education

Harbin, China

Email: hhswwjx@126.com

\section{Hui Li}

Research Center on Life Science and Environmental Science

Engineering Research Center of Natural Anticancer Drugs , Ministry of Education

Harbin, China

Email: huihui232@126.com

\author{
Xue Li \\ Research Center on Life Science and Environmental \\ Science \\ Engineering Research Center of Natural Anticancer \\ Drugs, Ministry of Education \\ Harbin, China \\ Email: 584276505@qq.com
}

Ruifeng E

Research Center on Life Science and Environmental Science

Engineering Research Center of Natural Anticancer

Drugs, Ministry of Education

Harbin, China

Email: 450536651@qq.com

\begin{abstract}
With rapid development of soybean industry in recent years in China, the soybean wastewater is doing greater and greater harm to the water environment. Now the SBR (Sequencing Batch Reactor) process has been widely used all over the world, and the SBR process is a biologic treating process of wastewater with simple structure and flexible operation. For example Anoxic/Oxic (A/O) process can be combined flexibly with SBR process. So in this paper in order to study the removal efficiency of soybean wastewater, the A/O SBR combined process was investigated with anoxic stir for $30 \mathrm{~min}$ and aeration for $3 \mathrm{~h}$. The MLSS was controlled at $2500 \mathrm{mg} / \mathrm{L}-3000 \mathrm{mg} / \mathrm{L}$ and sludge retention time (SRT) can be controlled in 12d-16d. The results showed that the concentration of COD, ammonia nitrogen, nitrite, nitrate and phosphate can reach $50 \mathrm{mg} / \mathrm{L}, 5 \mathrm{mg} / \mathrm{L}, 5 \mathrm{mg} / \mathrm{L}$, $4.5 \mathrm{mg} / \mathrm{L}$ and $1 \mathrm{mg} / \mathrm{L}$ respectively. Thus the A/O SBR process can obtain good effect for soybean wastewater treatment.
\end{abstract}

Keywords-Removal effect; A/O process; SBR process; soybean wastewater;
Xiaoyue Wang

Research Center on Life Science and Environmental Science

Engineering Research Center of Natural Anticancer Drugs , Ministry of Education Harbin, China

Email: 534047584@qq.com

\section{INTRODUCTION}

Since mid-1990s, the demand for vegetable oil, plant and animal protein has been increasing rapidly in China, so does the demand for soybean. China now is the world's largest consumer of soybean, and its soybean consumption reached 51.41 million tons in 2009.

Because of the increasing attention of state and governments at all levels on the environmental protection, China wastewater treatment industry is growing rapidly, total volume of wastewater treatment increases year by year, town wastewater treatment rate increases continuously, but at present, China wastewater treatment industry is still in the primary development stage.

On the one hand, capacity of China wastewater treatment can' t catch up with the rapid expansion of the water using scale, and construction of the matching equipment such as pipe network, sludge treatment, etc. lags behind seriously. On the other hand, there is an obvious gap between China wastewater treatment rate and 
the one in developed countries, and the load rate of treatment facilities is low.

With rapid development of soybean industry in recent years in China, the soybean wastewater is doing greater and greater harm to the water environment, moreover China is now speeding up the construction and operation of more and more wastewater treatment plants, and as a general rule the CASP (Conventional Activated Sludge Process) is mainly employed in city, where the land available for the construction of wastewater treatment plants is limited and expensive [1-4].

To overcome such problems, the SBR process has been widely used all over the world, and the SBR process is a biologic treating process of wastewater with simple structure and flexible operation, which can be completely mixed in space and ideally plug flow in time, and a variety of biochemical reactions can be completed in the same reactor, so the treating process become simplified, and infrastructure investment is significantly saved, and thus it is widely used in the treatment of living and industrial wastewater[5-7]. Thus the SBR has many advantages as follows [8]:

- The influent and effluent streams are uncoupled.

- Biomass separation occurs in the biological reactor and not in a separate clarifier.

- The unit operations and unit processes that take place in each reactor follow each other in a time sequence that is progressively repeated in a periodic" or -yclic" manner and not from tank to tank as they do in conventional process.

- A portion of treated water is periodically discharged from each tank to make room for a new batch of wastewater.

Nitrogen removal is accomplished by a two-stage treatment, aerobic nitrification and anoxic denitrification. And phosphorus removal is achieved through enhanced biological phosphorus removal. So this two-stage treatment process usually named Anoxic/Oxic (A/O) process. For nitrogen removal process, nitrate recirculation flow has long been identified as a manipulated variable in anoxic/oxic (A/O) process.

For A/O process, which is by far the most commonly used configuration for nitrogen removal, it has been found that controlling the nitrate nitrogen concentration at the end of the anoxic zone at a low set-point $(1 \sim 2 \mathrm{mg} / \mathrm{L})$ minimizes the amount of external carbon required, while maintaining the long-term average effluent nitrate nitrogen concentration at a pre-specified level.

So Anoxic/Oxic (A/O) process combined with Sequencing Batch Reactor (SBR) has an advantage of COD, nitrogen and phosphorus can be removal simultaneously. More studies have been showing that nitrification and denitrification can occur concurrently in one reactor under aerobic conditions with low dissolved oxygen (DO), through the so-called simultaneous nitrification and denitrification (SND) process. In addition, it has been reported that $\mathrm{N}$ removal can be achieved by partial oxidation of ammonium to nitrite.

In this paper in order to study the removal efficiency of soybean wastewater, the $\mathrm{A} / \mathrm{O}$ process and SBR process combined process was investigated.

\section{EXPERIMENTAL METHODS}

\section{A. The influent soybean wastewater characteristics}

The experimental wastewater was taken from sewage of a soybean food factory in Harbin. The influent wastewater characteristics were listed in Table 1.

TABLE I. INFLUENT SOYBEAN WASTEWATER CHARACTERISTICS

\begin{tabular}{|c|c|c|c|}
\hline COD (mg/L) & $\mathbf{p H}$ & $\mathbf{N H}_{\mathbf{4}}{ }^{+} \mathbf{- N}(\mathbf{m g} / \mathbf{L})$ & $\mathbf{P O}_{\mathbf{4}}{ }^{3-}-\mathbf{P}(\mathbf{m g} / \mathbf{L})$ \\
\hline $840-1050$ & $5.8-7.4$ & $48-72$ & $3-7$ \\
\hline
\end{tabular}

\section{B. Experimental equipment}

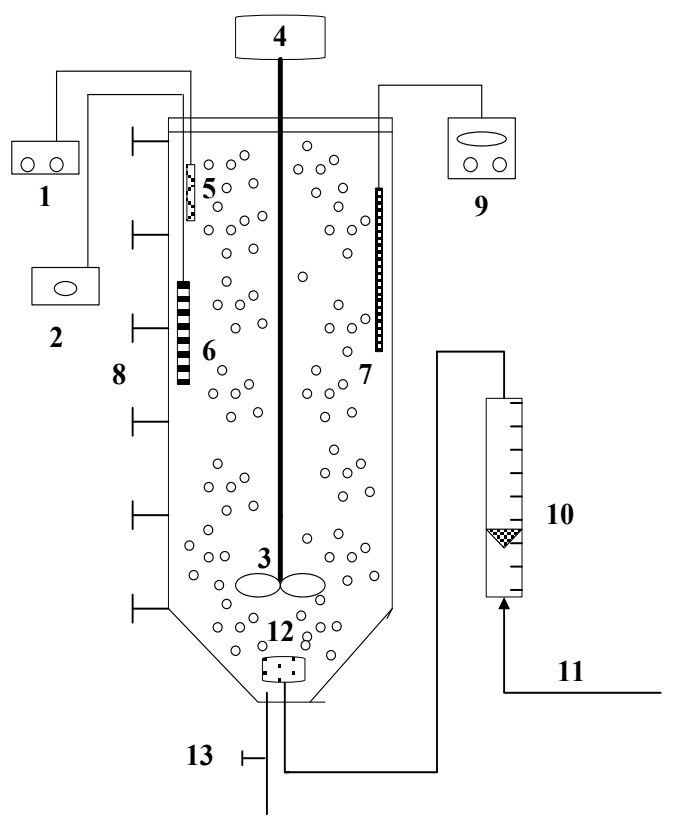

1.DO monitor 2. $\mathrm{pH}$ monitor 3. Stirrer 4. Adjuster 5. DO sensor 6. $\mathrm{pH}$ sensor 7. ORP sensor 8. Sample 9. ORP monitor 10. Gas flow meter 11. Influent air 12.Aeration diffuser 13. Discharged vessel

Figure 1. Schematic diagram of experimental equipment

The experimental instruments were shown in Fig .1. The experimental reactor was made of glass, and the volume of the reactor was $2 \mathrm{~L}$. There was a sampling device set on one side of the experimental installation for sampling and drainage. With a vessel at the bottom of the installation, it could discharge the excess sludge by drain pipe. The wastewater analytical methods were taken standard methods [9].

The $\mathrm{pH}, \mathrm{DO}$ and ORP online sensors were used to measure the variation of each indicator in the reactor. The experiment employed SBR process and instantaneous influent water, first anoxic stirring for $30 \mathrm{~min}$, then aerating for $3 \mathrm{~h}$, sedimentation for $2 \mathrm{~h}$ and drainage and lying idle for $2.5 \mathrm{~h}$.

The MLSS was controlled at 2500-3000 $\mathrm{mg} / \mathrm{L}$, operated 3 periods per day. Every period handled $0.5 \mathrm{~L}$ 
sewage, and mixed liquid of certain volume was emitted at the end of every period, with the sludge retention time (SRT) controlled in 12d-16d. The data of this experiment were all taken from the period after $30 \mathrm{~d}$, and data of this period were representative.

\section{Analytical methods}

Chemical oxygen demand (COD), alkalinity, ammonia nitrogen, nitrite, nitrate and phosphate were all analyzed following standard methods.

\section{RESULTS AND DISCUSSION}

\section{A. The COD removal effect}

During this period, COD in the system decreased obviously (shown in Fig .2), this is mainly because dilution effect of SBR process. After the anoxic stir for 30min, the COD decreased with the aeration. At the end of the reaction, the effluent COD was stable lower than $50 \mathrm{mg} / \mathrm{L}$. during this periods, the activated sludge in the reactor is very important for COD removal.

The activated sludge in this reactor with a brown floc, is largely composed of saprotrophic bacteria. But it has an important protozoan flora, which is mainly composed of amoebae, Spirotrichs, Peritrichs and a range of other filter feeding species. Other important constituents include motile and sedentary Rotifers.

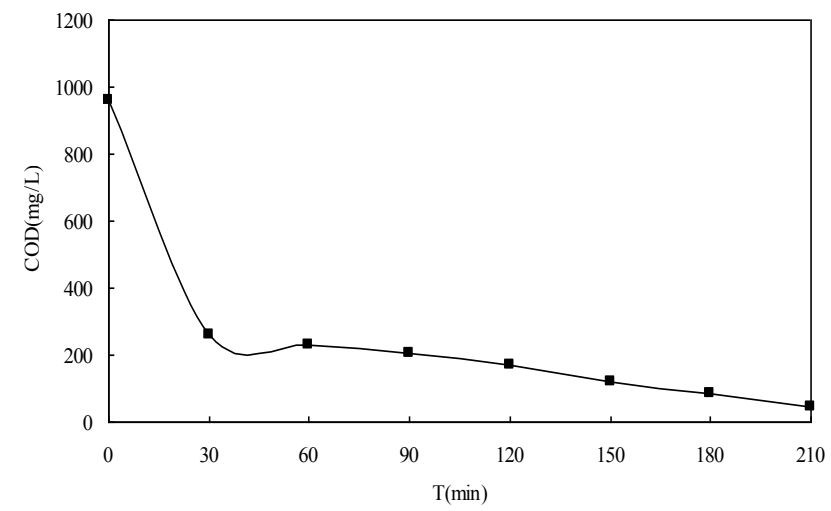

Figure 2. The COD concentration viration in a cycle

\section{B. The ammonia nitrogen removal effect}

The ammonia nitrogen in the system decreased obviously (shown in Fig .3), the ammonia nitrogen decreased after the anoxic stage. At the end of the aeration stage, the effluent ammonia nitrogen was stable lower than $5 \mathrm{mg} / \mathrm{L}$.

The ammonia nitrogen was removed by nitrifiers. And the ammonium is the major nitrogen compound of sewage and is removed in wastewater treatment plants[10]. Nitrification, the aerobic oxidation of ammonium to nitrate via nitrite, is catalysed by two different groups of slow-growing, autotrophic bacteria - the ammonia oxidisers and the nitrite oxidisers[11-12]. There is considerable interest in understanding the ecology of nitrifying bacteria because nitrification is the Achilles heel of many wastewater treatment plants, although the causes for nitrification breakdown events are not always obvious. Once nitrifiers have been washed out of a WWTP, recovery of the nitrification process can take very long time periods owing to the slow growth rates of the nitrifiers[12].

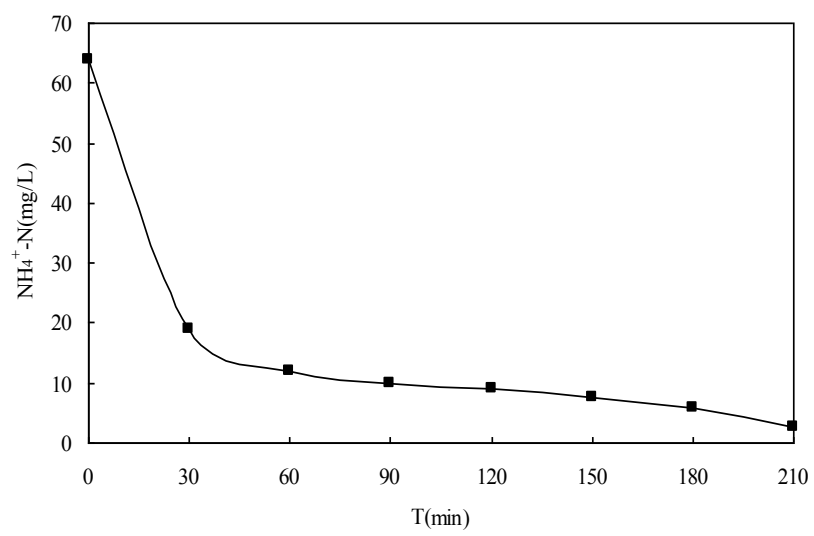

Figure 3. The ammonia nitrogen concentration viration in a cycle

\section{The nitrite variation in a cycle}

At the initial period, the nitrite in the system was about zero. At the end of anoxic stage, the nitrite concentration increased about $1 \mathrm{mg} / \mathrm{L}$ (shown in Fig .4). Furthermore the nitrite concentration increased until the aeration stage stopped. At the end of the aeration stage, the effluent nitrite was about $5 \mathrm{mg} / \mathrm{L}$.

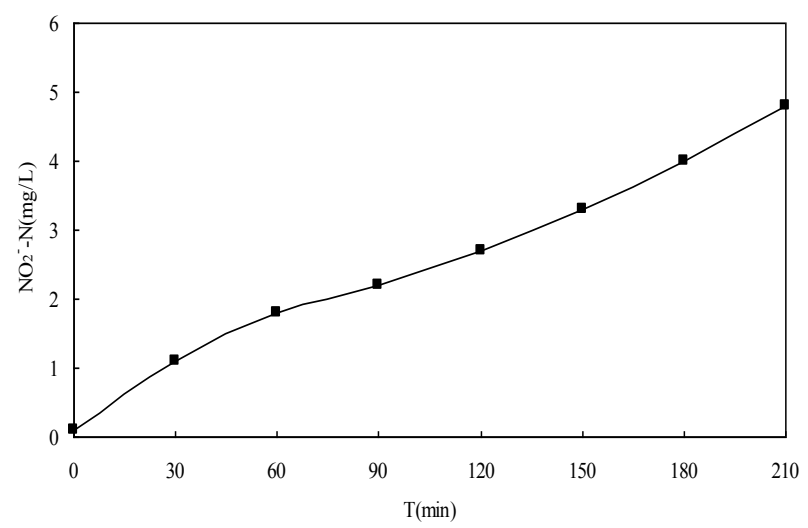

Figure 4. The nitrite concentration viration in a cycle

\section{The nirate variation in a cycle}

The nitrate vibration tendency was the same as the nitrite. At the initial period, the nitrite in the system was about zero. At the end of anoxic stage, the nitrite concentration increased about $2 \mathrm{mg} / \mathrm{L}$ (shown in Fig .5). Furthermore the nitrite concentration increased until the aeration stage stopped. At the end of the aeration stage, the effluent nitrite was about $4.5 \mathrm{mg} / \mathrm{L}$. 


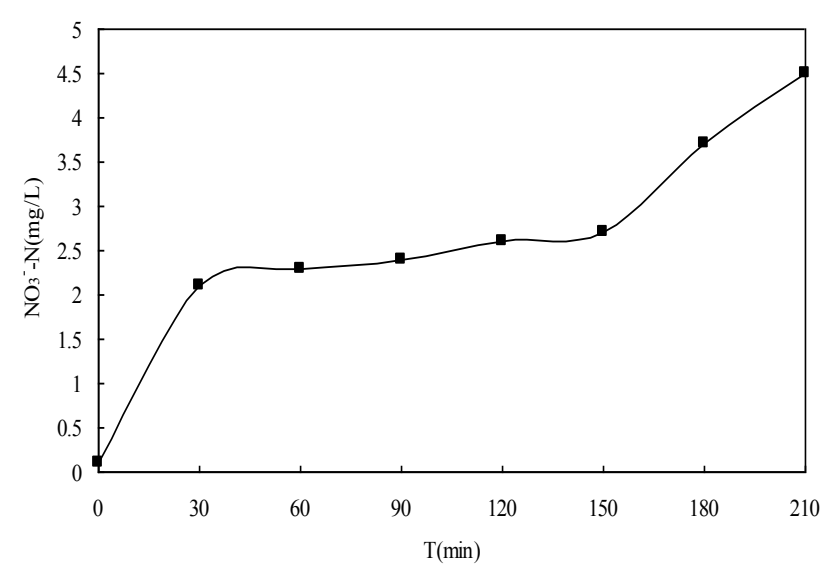

Figure 5. The nitrate concentration viration in a cycle

\section{E. The phosphate removal effect}

At the initial period, the phosphate in the system was about $5.8 \mathrm{mg} / \mathrm{L}$. At the end of anoxic stage, the phosphate concentration increased about $16 \mathrm{mg} / \mathrm{L}$ (shown in Fig .6). Then the phosphate concentration decreased until the aeration stage stopped. At the end of the aeration stage, the effluent nitrite was lower than $1 \mathrm{mg} / \mathrm{L}$.

Usually a carbohydrate and an organic acid mixture are used as carbon and energy sources in biological nutrient removal. Phosphate removal can be seen not only as a way of removing phosphate pollution, but also as an efficient method of removing organic carbon.

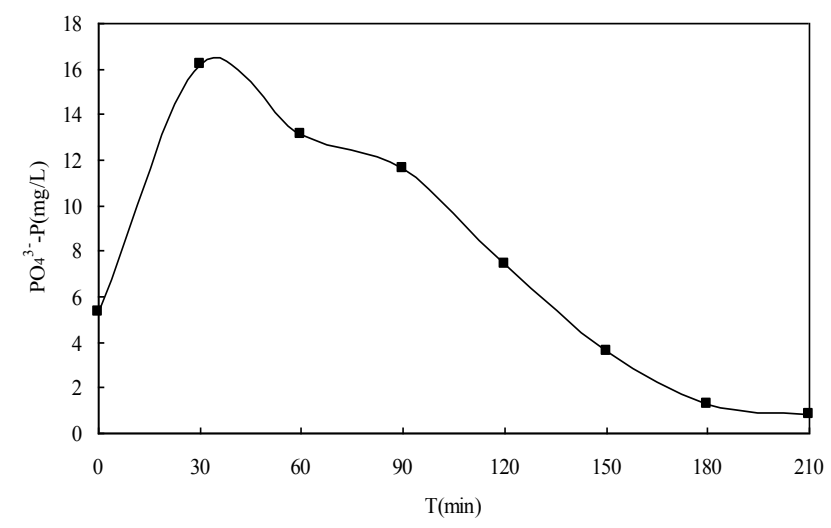

Figure 6. The phosphate concentration in a cycle

\section{CONCLUSION}

1. During this period, COD in the system decreased obviously, after the anoxic stir for $30 \mathrm{~min}$, the COD decreased with the aeration. At the end of the reaction, the effluent COD was stable lower than $50 \mathrm{mg} / \mathrm{L}$.

2. The ammonia nitrogen decreased after the anoxic stage. The trend of ammonia nitrogen decreased is similar to COD. At the end of the aeration stage, the effluent ammonia nitrogen was stable lower than $5 \mathrm{mg} / \mathrm{L}$.

3. The nitrite variations in a cycle are similar to a nitrate in many respects. At the end of the aeration stage, the effluent nitrite and nitrate was about $5 \mathrm{mg} / \mathrm{L}$ and $4.5 \mathrm{mg} / \mathrm{L}$ respectively.

4. The phosphate in the system increased at the initial period, and then it decreased in the aeration stage. At the end of anoxic stage, the phosphate concentration increased about $16 \mathrm{mg} / \mathrm{L}$. Then the phosphate concentration decreased until the aeration stage stopped.

Through the experiment data, the removal effect of A/O SBR process for soybean wastewater was good. The concentration of COD, ammonia nitrogen, nitrite, nitrate and phosphate can reach $50 \mathrm{mg} / \mathrm{L}, 5 \mathrm{mg} / \mathrm{L}, 5 \mathrm{mg} / \mathrm{L}, 4.5 \mathrm{mg} / \mathrm{L}$ and $1 \mathrm{mg} / \mathrm{L}$ respectively. Thus the A/O SBR process can obtain good effect for soybean wastewater treatment.

\section{ACKNOWLEDGMENT}

This research is financially supported by Natural Science Foundation of Heilongjiang Province of China (NO. E201355).

\section{REFERENCES}

[1] A.C Rodrigues, G. Antonio and Melo Luis F. Posttreatment of a brewery wastewater using a sequencing batch reactor," Wat. Environ. Res. , vol.73, 2001, pp. 45-51

[2] J. A Pierson and S. G Pavlostathis. Real-time monitoring and control of sequencing batch reactors for secondary treatment of apoulty processing wastewater," Wat. Environ. Res. vol.72, 2000, pp.585-592

[3] I. A Ghusain, J. Huang, O. J Hao and B. S Lim. Using pH as a real time control parameter for wastewater treatment and sludge digestion process," Wat. Sci Tech, vol.30, 1994, pp. $159-168$

[4] F. Lefevre, J. M. Audic and B. Bujon. Automatic regulation of activated sludge aeration-single-tank nitrification denitrification," Wat Sci Tech, vol.28, 1993, pp.289-299

[5] J. Chapentier, G. Martin and H. Wacheux. @RP regulation and activated sludge: 15 years of experience," Wat. Sci.Tech., vol.38, 1998, pp.197-208

[6] B. S. Akin and A. Ugurlu. Monitoring and control of biologicalnutrient removal in a sequencing batch reactor," Process Biochem., vol. 40, 2005, pp. 2873-2878

[7] F. Y. Rue, L. S. Liang and C. C. Nan. Applying real-time control to enhance the performance of nitrogen removal in the continuous flow SBR system,” Wat. Sci.Tech., vol. 38,1998, pp. 271-280

[8] P. A. Wilderer, R. L. Irvine and M. C. Geronszy. Sequencing Batch Reator Technology," IWA Publishing: London, UK, 2001, pp.1-3.

[9] APHA, Standard Methods for the Examination of Water and Wastewater," 20th ed., American Public Health Association: Washington, DC, USA, 1998, pp.89-93.

[10] Figueroa M, Mosquera-Corral A, Campos J L, et al Treatment of saline wastewater in SBR aerobic granular reactors[J]. Water Science and Technology, 2008, 58(2): 479.

[11] De Kreuk M K, Heijnen J J, Van Loosdrecht M C M. Simultaneous COD, nitrogen, and phosphate removal by aerobic granular sludge $[\mathrm{J}]$. Biotechnology and Bioengineering, 2005, 90(6): 761-769.

[12] Michael W. and Alexander L. Bacterial community composition and function in sewage treatment systems[J]. Environmental biotechnology, 2002, 13:218-227 